\title{
Reinventar a Foucault. Una mirada arqueo-genealógica a la historia de la educación física y el deporte escolar en España \\ Reinventing Foucault. An archaeo-genealogical look at the history of physical education and school sports in Spain \\ *Marta Mauri Medrano y **Xavier Torrebadella \\ *Universidad de Zaragoza (España), **Universidad Autónoma de Barcelona (España)
}

\begin{abstract}
Resumen: En el transcurso del tiempo se ha producido todo un descubrimiento del cuerpo como objeto y blanco de poder. Un cuerpo que se manipula, al que se le da forma, que se educa, que obedece y que se somete. En toda sociedad, el cuerpo queda prendido en el interior de poderes muy ceñidos, que le imponen coacciones, interdicciones u obligaciones. Surgieron así métodos que permitían el control minucioso del cuerpo, dispositivos de control que pretendían normalizar ciertas prácticas, en el marco de la educación física y el deporte, donde el encuadramiento, los horarios y las taxonomías, los ejercicios de gimnasia y las prácticas escolares, le asignaban así a cada cuerpo un sitio definido y lo sometían a un control incesante. Foucault elaboró una «microfísica del poder»: la formación, el modelado de los cuerpos, se difundían en una sociedad por el sesgo especialmente de la escuela, del ejército, del hospital, lugares todos donde irradiaban normas y vigilancia continua y sistemática. Con este artículo se pretende «reinventar a Foucault» utilizando su «caja de herramientas» teórica para comprender los entresijos que la educación física y el deporte a lo largo de la historia.
\end{abstract}

Palabras clave: Michel Foucault; Poder; Códigos disciplinares, Educación física; Deporte.

Abstract: Over the course of time, the body has been discovered as an object and target of power. A body that is manipulated, shaped, educated, obeyed and subjected. In any society, the body is caught up in the tightly bound powers that impose coercion, interdictions or obligations on it. This led to the emergence of methods that allowed for the meticulous control of the body, control devices that sought to normalise certain practices, in the framework of physical education and sport, where the framework, timetables and taxonomies, gymnastic exercises and school practices, thus assigned each body a defined place and subjected it to incessant control. Foucault elaborated a «microphysics of power»: the formation and modelling of bodies was disseminated in a society through the bias of the school, the army, the hospital, all of which radiated norms and continuous and systematic surveillance. This article aims to «reinvent Foucault» by using his theoretical «toolbox» to understand the intricacies of physical education and sport throughout history.

Key words: Michel Foucault; Power; Disciplinary codes; Physical education, Sport.

\section{Introducción}

Según Foucault (2012), en la sociedad circulan tecnologías y procedimientos para controlar a los individuos y hacerlos a la vez «dóciles» y «útiles», la educación física y el deporte serían algunos de ellos. Como explicaba Foucault, existe una economía política del cuerpo, incluso cuando no hay violencia explícita y se utilizan otro tipo de métodos que encierran o corrigen; pero siempre es del cuerpo del que se trata, y de sus fuerzas, de su utilidad y su docilidad, de su distribución y su sumisión. El cuerpo, para Foucault, está inmerso en un campo político ya que las relaciones de poder operan sobre él; dichas relaciones lo marcan, lo cercan, lo doman, lo someten, lo fuerzan a unos trabajos, lo

Fecha recepción: 23-09-21. Fecha de aceptación: 11-01-22

Marta Mauri Medrano

mmauri@unizar.es obligan a unas ceremonias, exigen de él unos signos. Existe, entonces, una utilización económica del cuerpo (Foucault, 2009).

Para Michel Foucault, la descripción arqueológica es el abandono de la historia de las ideas, el rechazo sistemático de sus postulados y de sus procedimientos, la tentativa para hacer una historia distinta de lo que los hombres han dicho (Foucault, 2002, pp. 232-233). Como no podría ser de otro modo, y teniendo presente el estudio de Veyne (1984), Foucault ha revolucionado el modo de ver y hacer historia; aún más, ha dotado al saber/poder de los historiadores de las herramientas para hacer una historia más verdadera, más cercana a lo humano, a la vez que más irreverente a las instituciones de los poderes fácticos.

Hace ya unos años que Cuesta (2013) nos invitó a reinventar al Foucault crítico para desestabilizar el pensamiento pseudocrítico o (a)crítico del presente, en cuanto a la educación física y el deporte se refiere. Sobre esta proposición, del mismo modo que Foucault, 
hay que advertir que la intención de esta tarea es parte de un bricolage rudimentario e inacabado, y no es más que una pequeña fracción de una compleja cartografía en continua reelaboración. El objetivo de este artículo pretende atender, como sugiere Vicente (2012, p. 92), a delimitar «los códigos disciplinares de la educación física mediante un análisis de largo alcance -tal vez genealógico- que permita comprender las estructuras simbólicas y materiales, los dispositivos tanto teóricos como prácticos que le dan forma curricular».

\section{Metodología}

El historiador comprometido lleva la mirada genealógica con un propósito intelectual crítico y pedagógico, porque saca a la luz y pone en juego una historia -o contrahistoria - con memoria - de contramemoriay advierte de las peligrosas resonancias de un pasado no pasado que conviene significar en presente. De aquí que se hable de la historia del presente como antídoto al ahistoricismo que gobierna las ciencias sociales (Castel, 2013).

Esta mirada foucaultiana parte del uso de esa «caja de herramientas», legada por el filósofo de Poitiers, para «cortocircuitar, descalificar, romper los sistemas de poder» (Foucault, 1991, p. 88) en el marco de la educación física y el deporte. Asimismo, abordando la «Historia del Detalle» (Foucault, 2012b, p. 163), de «las pequeñas verdades sin apariencia» (Foucault, 2014, p. 12), en los discursos de la educación física y el deporte escolar podemos encontrar la exégesis de los sistemas y códigos disciplinares invisibilizados.

Llegados a este punto, vamos a conferir un relato a través de la incautación hermenéutica foucaultiana, es decir, abordar una metodología histórico-crítica y arqueo-genealógica a partir de este autor refiriéndonos al análisis en la educación física y el deporte escolar utilizando un enfoque histórico-genealógico para estimular los textos retrospectivos seleccionados con la inspiración de las investigaciones publicadas en el contexto español (Cuesta, 2014; Mateos y Mainer, 2019; Viñao, 2016).

Es precisamente en esta mirada en la que podremos encontrar, como ya están estableciendo otros autores (Emiliozzi, 2016; Galak, 2013; Kopelovich, 2019; Pich y Rodríguez, 2014; Pich y Vicente, 2021; Rodríguez Giménez, 2003, 2010), las paradojas de la epistemología de la educación física y el deporte que se han dotado de códigos disciplinarios que han normalizado nuestro marco mental educativo.

\section{Código y dispositivos disciplinares en la edu- cación física escolar}

Los distintos poderes en ejercicio, es decir, el pedagógico, el religioso, el médico, el militar, el político o el económico, todos ellos parten de intereses diferentes, pero comparten dispositivos disciplinarios semejantes. Son «mecanismos infinitesimales que tienen su historia, su trayecto, su técnica y su táctica» (Foucault, 1998, p. 32). Existe una compleja relación de interdependencia entre todos ellos, por lo que configuran redes globales de dominación en las que se halla inmersa la acción docente del profesorado de educación física.

Toda disciplina necesita de elementos técnicos constituyentes o dispositivos normalizadores de las prácticas. Estos elementos tienen muchas finalidades y configuran la microfísica del saber/poder del discurso disciplinario. En primer lugar, vamos a seleccionar esos códigos -o dispositivos disciplinares- (Cuesta, 2007) que se establecieron en la educación moderna. El primero de todos ellos es el encierro total; es decir, la idealización sobre el sentido de la educación pública, con lo cual el Estado tomaba a su cargo a todos los elementos susceptibles de la instrucción y de la educabilidad. Pero este encierro ya se había estructurado en los colegios-internados seglares del liberalismo decimonónico; se trataban de los niños y niñas burgueses destinados a ocupar los mejores puestos de la sociedad. Naturalmente, sometidos a un encierro de vigilancia panóptica y permanente sobre las tareas y de todo cuanto acontece $\mathrm{y}$, adoctrinados, en primer lugar, por una rutinaria y sistemática ejercitación sobre el cuerpo.

La dominación de la actitud corporal que empieza por la quietud y el silencio, que continúa con la escritura, la lectura y el canto, la gimnástica y el reposo, la norma y la sanción gobiernan y se imponen en los reglamentos de los colegios, que son también los reglamentos del cuartel, de la fábrica o de los hospitales. Al dictado escrito de la obediencia jerárquica es seguido por el recuento de las faltas, de las lógicas del premio y del castigo disciplinario, por el rigor de la letra perfecta, la obsesión por la gramática, la correcta dicción, la memoria y la oratoria. Las relaciones del éxito y el fracaso -o del bien y del mal- sí, del fracaso - que ya es castigo por sí mismo-es irracionalmente castigado, con lo cual, este sistema refuerza la selección natural de los más fuertes y afortunados y, la humillación de los perdedores. Y es aquí cuando se edifica la pedagogía del modelo, el retablo del buen soldado, del perfecto cristiano, del perfecto caballero, del gentleman y del sportsman o del ideal de «hom- 
bre nuevo».

\section{El poder pedagógico-religioso. La racionalidad} de los juegos vigilados

Los juegos de los niños recrean la ilusión de la libertad en el mundo; son los juegos de la inocencia, esos juegos lícitos que el adulto ha inventado y ha institucionalizado para los aprendizajes ulteriores de la vida que aguarda. Estos juegos reúnen los códigos disciplinares de las relaciones permitidas -moralmente normalizadas- en un contexto social jerarquizado de dominación religiosa y patriarcal. Estos juegos son los dispositivos del poder disciplinar de una sociedad civilizada y punitiva; juegos en los que se infieren normas de conducta, saberes morales y mitos, cuyo objeto no es otro que el de preservar el orden social y soberano. Ahora bien, hay que distinguir claramente entre aquellos juegos de niñas y los juegos de niños. De aquí que muchos de estos juegos permanecieran inalterados durante siglos incrustados en nuestras sociedades (Brasó y Torrebadella, 2015, 2017a, 2018, 2019a).

Pero también existen aquellos juegos prohibidos, los que molestan a los adultos, a los transeúntes, juegos que entrañan peligro que pueden ser sancionados con multas o arrestos en correccionales, como sucedía con el juego del bélit en la Barcelona de mediados del siglo XIX (Ayuntamiento de Barcelona, 1839, 1857). Algo que también sucedió con el juego de pelota y más tarde con el juego del fútbol.

Así se institucionalizan los patios o campos de juego escolares. Primero en los colegios internados de la burguesía, luego en los colegios públicos, siempre más limitados, y más tarde en los espacios públicos y fuera del entorno escolar. En los parques infantiles, suelen disponer de bancos para el descansar de los adultos y, naturalmente, para una confortable vigilancia de los y las menores. Así, los recreos se convirtieron en espacios y tiempos vigilados, encuadrados en el marco pedagógico del surmenage y en la subordinación de los juegos a las normas morales y los dispositivos normalizadores de las conductas deseadas (Brasó y Torrebadella, 2017b).

\section{El poder médico. La gimnasia y la corrección del cuerpo}

Las deducciones de Foucault (2001a) sobre el análisis de contenido de los textos médicos en el ejercicio político de la profesión mostró el discurso del saber/ poder en este campo. La observación o «examen clínico» sobre el organismo - o sujeto- enfermo emprenden desde el detallado registro médico, las interpreta- ciones y el diagnóstico de las enfermedades.

Con la aparición de la medicalización gimnástica a finales del siglo XVIII, el gimnasio decimonónico se configuró como una extensión privada de la clínica que también salvaba de la degeneración y de la muerte; por eso se impuso el gimnasio higiénico, médico y ortopédico bajo una presencia facultativa para asegurar la conveniente prescripción del ejercicio.

En los gimnasios también se anotaba toda la intervención técnica y se registran los datos de progreso fisiológico; el profesor de gimnástica se convirtió en la autoridad del ejercicio físico. Por lo tanto, el gimnasio higiénico fue antes que nada educativo, correctivo y preventivo de los «males funestos» (Vicente-Pedraz y Torrebadella-Flix, 2019). Por eso su pronta instalación hacia a mediados del siglo XIX en los colegios internados de la burguesía; eso sí, sujetos a la mirada científica del médico (Vicente-Pedraz y Torrebadella-Flix, 2017), que ordenaba además todo un régimen normativo técnicas de vigilancia- de disciplina militar y monacal.

En estos internados escolares de austeridad y de disciplina espartana, el objeto de atención sobre el cuerpo fue la piedra angular de la buena educación (TorrebadellaFlix y Vicente-Pedraz, 2016; Vicente-Pedraz y Torrebadella-Flix, 2015). Pero a cambio de dominar y fortalecer la voluntad se perdió, la libertad y la inteligencia emocional y se engendró el monstruo de la emulación, es decir, la esencia ideológica del colonialismo y el capitalismo. La gimnástica y el ejercicio físico en general fue concebido en estos colegios como el mejor antídoto contra la masturbación (Torrebadella-Flix y Vicente-Pedraz, 2016; Vicente-Pedraz y TorrebadellaFlix, 2015) y, por consiguiente, el mito de la educación física se convirtió en un dispositivo disciplinar que buscaba «la pedagogización del sexo del niño» (Foucault, 2012a, p. 100).

Por lo tanto, la gimnástica, como el deporte, se idealizaron como los antídotos de una incompleta pedagogía, subordinada a un paradigma biológico ultramontano; en el trasfondo de la cruzada contra el onanismo existía una preocupación mucho mayor que la degeneración: si en parte se castigaba la afeminación y la homosexualidad, no era menos preocupante la disidencia de contravenir el orden social de la autoridad establecida.

\section{El poder político. La biopolítica y la normaliza- ción}

En España las políticas educativas, sanitarias y de beneficencia a la infancia surgieron como respuesta tar- 
día a la pedagogía social de la clase obrera o, mejor dicho, para minimizar los riesgos de la «plebe sediciosa» o de «las clases peligrosas» (Foucault, 2018, p. 156 y 188), cuyo fantasma horrorizaba la cotidianidad de la vida burguesa. Había que proteger pues el espacio público de los centros urbanos y ocultar la inmoralidad que arrastraba la muchedumbre desarraigada (Huertas, 1998). La modelación urbanística de las ciudades modernas se configuró en una lógica de la división del territorio, que por un lado respondía al ensanche de viviendas por el derrumbe de las viejas murallas y, por el otro a las necesidades del crecimiento industrial. Naturalmente, la burguesía buscó espacios residenciales más saludables y alejados del gentío, sobre todo del fantasma de la corrupción y la degeneración (Calvo, 2012). La llamada protección a la «infancia en peligro» fue, por un lado, un paliativo de higiene social y, por el otro, un abastecimiento del stock de la mano de obra barata y disciplinada; y no tanto una intervención de sincera beneficencia. Lo que realmente preocupaba era la «infancia peligrosa», aquella que podía atentar contra el orden público.

La escuela aparece entonces como una pieza básica en la construcción del orden social, como un espacio de "civilización» y de "moralización» de los hijos de los trabajadores que, a diferencia de la infancia rousseauniana, nacían con el estigma de la peligrosidad y la degeneración.(Huertas, 1998, p. 162)

De aquí la creciente, pero siempre precaria e insuficiente, red de escuelas públicas de primera enseñanza para las clases subalternas, los asilos de infancia, los orfanatos, los correccionales de menores o las colonias escolares que se alinearon como lugares idóneos para investigar sistemas de normalización disciplinaria sobre una población frágil, es decir, como laboratorios para la 'gubernamentalidad' (Foucault, 2008).

A principios del siglo XX en Barcelona surgen las instituciones de preservación, reforma y rehabilitación, es decir, centros para rehabilitarse en la sociedad. Allí se agrupaban, según determinaba la autoridad, a las niñas o «jóvenes licenciosas», «desviadas de la vida», «jóvenes extraviadas del vicio», «jóvenes de vida airada». Allí los medios empleados eran «la dulzura, la vigilancia continua, la instrucción religiosa y elemental, confección de labores y todo cuanto atañe a la educación de la mujer» (Ayuntamiento de Barcelona, 1914, p. 329). En la Real Casa de Retiro - fundada en 1740- tenía por objeto «arrancar del vicio a las mujeres que a él se han entregado y salvar a las que se encuentren en peligro o próximo a caer en el» (Ayuntamiento de Barcelona, 1914 , p. 330).
En el reformatorio de Elmira en los Estados Unidos se establecieron los ejercicios militares de un modo persistente para acostumbrar a los reclusos a la disciplina, talleres profesionales para aprender un oficio y «la educación física, dada científicamente en un gimnasio por instructores de gran competencia y bajo la dirección del Médico del Establecimiento» (Cadalso, 1898, p. 31). Efectivamente, los modelos penitenciarios de los Estados Unidos de Norte América eran muy observados (Dorado, 1898), y se destacaba la incorporación de los ejercicios gimnásticos y, en especial, de la gimnástica sueca, como dispositivo de poder disciplinario:

Sin duda para hacer firme la disciplina se somete a los educandos durante el primer tiempo de su estancia en el Reformatorio a la gimnasia militar.Ya hemos dicho en la Revista, al hablar del establecimiento de alcohólicos de Foxboro, que la gimnasia sueca es estimada como el mejor fortificante de la voluntad. (Salillas, 1905b, p. 730)

Por parte de los chicos, existía el Asilo Durán -constituido en 1890- «para niños díscolos y rebeldes para quienes haya sido infructuosa la corrección paterna» (Ayuntamiento de Barcelona, 1914, p. 330), pero este correccional era considerado modélico por la buena instrucción y educación que allí se ofrecía (Alijo, 1902).

Todo lo que se refiere a protección y educación de la infancia desvalida, estaÀ en España casi por hacer. Aquí el esfuerzo oficial es insuficiente ò̀ estaÀ organizado con aridez para retener en su ambiente aÀ esa multitud dè̀ niños abandonados que viven en el arroyo. (Barrenillo, 1917, p. 10).

En Madrid, fue muy destacable el Asilo de Porta Coeli, fundado y dirigido por el sacerdote Francisco de Asís Méndez Casariego (1850-1924), también como correccional de «golfos». Allí se decía atender una obra de «pedagogía social» (Barrenillo, 1917, p. 10):

No se olvida el desarrollo físico; los juegos de deportes, ejercicios gimnásticos, marchas militares, etc., constituyen la educación física, que al mismo tiempo que contribuye o la recreación, es medio de tenerlos distraídos durante el tiempo que las clases y los oficios no reclaman su atención. (De Cossío, 1919, p. 31)

En estas instituciones, las organizaciones de los espacios, de los tiempos, de las tareas, de las acciones o de los silencios, configuraban el ejercicio rutinario de una disciplina de obediencia en un entorno normativo y estrechamente vigilado, como ya hicieran los colegios de jesuitas y las escuelas lancasterianas. En estos centros de confinamiento, el poder de la 'gubernamentalidad' compartida entre párrocos, médicos, pedagogos y el encarecido maestro de gimnástica se hacía altamente significativo para la acción biopolítica aparente: salvar a la infancia. Todos estos sujetos ejercían las técnicas 
disciplinares particulares de su campo, pero que algo en común poseían:

La disciplina, desde luego, analiza, descompone a los individuos, los lugares, los tiempos, los gestos, los actos, las operaciones. Los descompone en elementos que son suficientes para percibirlos, por un lado, y modificarlos, por otro. (...) la disciplina clasifica los elementos así identificados en función de objetivos determinados. (...) La disciplina establece las secuencias o las coordinaciones optimas: cómo encadenar los unos con otros, cómo repartir a los soldados para una maniobra, cómo distribuir a los niños escolarizados en jerarquías y dentro de clasificaciones (...). La disciplina fija los procedimientos de adiestramiento progresivo y control permanente y por último, a partir de ahí, distingue entre quienes serán calificados como ineptos e incapaces y los demás (Foucault, 2008, p. 65).

Por lo tanto, la educación física, acorde siempre por las prescripciones morales e higiénico-medicas, entraba a regular el campo propio de corporalidades: los ejercicios gimnásticos, los paseos escolares, los baños higiénicos, los juegos normativos, las colonias veraniegas o los batallones infantiles, formaban el elenco de contenidos para fortalecer la voluntad, endurecer el cuerpo y sembrar la virtud (Torrebadella, 2013, 2015; Torrebadella-Flix y Brasó, 2017). Efectivamente, sobre estos elementos, como trata Foucault (2012b, p. 160), se activaban los dispositivos coercitivos del encarcelamiento, las técnicas de vigilar-castigar para fabricar los «cuerpos sometidos y ejercitados, cuerpos dóciles».

Aquí no fueron menos los festivales de educación física en la que los escolares, salvados por la sociedad, desfilan a ritmo y paso militar, con cantos patrióticos para ser examinados ante la ciudadanía - ante el soberano- y mostrar la lozanía de la reserva bélica y de la obra patriótica bien concebida (Ayala, y Zagalaz, 2016; Torrebadella y Inglés, 2021). En palabras de Foucault (2012b, p. 223), podríamos decir que en estos festivales-examen -formas fastuosas como el desfile de súbditos ante el soberano- muestran «el objeto y el efecto del poder», es decir, el sumatorio de corporalidades abnegadas - de súbditos-por un cuerpo único, pero que se configura a través de «la fabricación de la individualidad celular, orgánica, genética y combinatoria».

\section{El poder militar. Juegos de la muerte}

Desde finales del siglo XIX los batallones infantiles y los juegos por la patria institucionalizaron los deseos de la militarización escolar. Aparte de las instancias militares, entre las figuras más representativas deseo destacar la del sacerdote y catedrático de derecho de la Universidad de Granada Andrés Manjón (1846-1923), el cual debería ser considerado el principal impulsor ideológico que a través de los batallones infantiles configuró el dispositivo gimnástico-militar-patriótico más importante de la educación física antes del franquismo. La cuestionada semblanza pedagógica - demagógica- de Manjón ha pasado a la historia de la educación española por su significativa obra de beneficencia educativa. Ahora bien, las sombras de este venerado maestro burgalés »castellano viejo»- que trató de españolizar y castellanizar en nombre de la de raza española: «hombres católicos, cabales y completos» (Torrebadella y Brasó, 2019b, p. 146), aún están por especificar.

Manjón estuvo persuadido, que por los tiempos que corrían, había que instruir a los niños a la guerra -como si de un juego se tratase-. Un juego en los que aparte de las típicas paradas militares, maniobras y cantos, también se enseñaba a los pequeñuelos uniformados a clavar la bayoneta a sangre fría a un enemigo imaginario, pero con nombre: infieles, separatistas, masones, judíos, liberales, socialistas, anarquistas, homosexuales, antihumanos, anti-españoles... Naturalmente, la suerte de estos pobres niños de condición humilde corría paralela a la obediencia y docilidad que pudieran demostrar; y allí se encontraba también la condición de morir por la gloria de una patria imaginada.

A partir de aquí, en consecuencia, a la coyuntura sociopolítica del momento, la escuela entró a configurar un esencialísimo engranaje para institucionalizar la mecanización la guerra (Torrebadella, 2022). Las tendencias hacia la militarización total, a través de una gimnástica sueca, asociaciones de batallones infantiles, instituciones como el Tiro Nacional (Torrebadella, 2018) o Los Exploradores de España, con sus acampadas y juegos de trivialización de la guerra como el de «la bandera» (Ros y Torrebadella-Flix, 2021), o el fútbol (Torrebadella, 2017, 2018, 2020), corroboraban el poder genealógico de la guerra civil o de todos contra todos (Foucault, 2018).

Sobre estas instituciones disciplinares es cuando se repara en Foucault (2012, p. 161), al divisar que «la disciplina es una anatomía política del detalle». En efecto, estas organizaciones, como ya dijimos en otra ocasión, son lo que Foucault (1998, p. 73) denominó los modernos dispositivos del «racismo de Estado», dicho de otro modo, el aprovechamiento biopolítico sobre la vida y la muerte de los que no ejercen el poder.

\section{El poder económico. El deporte escolar y Clausewitz \\ El médico y filósofo Huarte de San Juan (1529-1588)}


criticó el sistema de emulación - dispositivo de emulación- utilizado por los jesuitas- en Examen de Ingenios para las ciencias $(1594)^{1}$. Huarte dudó de la eficacia de la emulación y de los premios, puesto que no representaban los méritos propios por igualdad porque «entraban en competencia dos diferentes ingenios (...) es como si pusieren premio a dos corredores, y el uno tuviese buenos pies ligeros, y al otro le faltase una pierna» (Huarte, 1594, p. 285; 1593, p. 211 bis).

El deporte apareció en la escuela burguesa en parte para soportar mejor el régimen carcelario que en ella existía. Ahora bien, el juego deportivo fue el dispositivo disciplinario más eficaz para re-recrear una falsa ilusión de libertad, para satisfacer la autorrealización personal o la mitificada y elitista visión pedagógica del selfgovernment del reverendo Thomas Arnold (1795-1842) en la escuela de Rugby. Por su parte, en Eton College, el Dr. Jonh Keate (1773-1852) impuso también un férreo y austero sistema de endurecimiento intelectual, moral y físico y así fue como en estos colegios se instruyeron los grandes hombres del imperio británico (Russell, 1988) como refleja la famosa frase el Duque de Wellington cuando mencionó que la batalla de Waterloo contra Napoleón -el 18 de julio de 1815- ya se venció en el campo de juego de Eton:

Wellington sobresalió más que en otra cosa en el colegio de Eton, por su vigor y agilidad en los juegos; y con razón dijo al ver, ya anciano, jugar a los jóvenes en el campo contiguo a este colegio: Aquí se gano la batalla de Waterloo. (Díaz de Benjumea, 1866, p. 16)

Como en Inglaterra y en otras naciones de Europa, también en España, los internados escolares tenían por cometido masculinizar al hombre, es decir, evitar su inclinación al vicio de la masturbación, la afeminación y la homosexualidad. Eso cuando la heterosexualidad estaba completamente impedida, pero al contrario existía la latente posibilidad de una homosexualidad, en tanto que su prohibición no materializaba el impedimento y, por eso, se ejercía «un sobrecontrol sobre los individuos y poder someterlos, en su vida corporal, afectiva, privada, a algo semejante a un control, una vigilancia perpetua» (Foucault, 2018, p. 234) de todos los detalles.

Por ejemplo, la técnica científica de adiestrar el movimiento humano. En primer lugar, se desprende la norma de la observación en detalle - del ejercicio panóptico, en segundo lugar, la norma de la medición ya sea del propio cuerpo humano -la antropometría- o de las manifestaciones del movimiento - capacidades condicionales y coordinativas-; todo debe estar mesurado - ya en su aspecto cuantitativo como cualitativo-. La norma del registro, la baremación, la clasificación y la comparación y, posteriormente, la norma de la corrección, la de corregir y enderezar el cuerpo (Vigarello, 2005).

Para terminar, la norma del examen público o la competición cierra el círculo de un proceso continuo en la norma de la repetición del ejercicio hasta la mecanización perfecta del movimiento y del máximo rendimiento. Es pues en este paradigma que se etiquetan a los sujetos, eso sí, a partir sus manifestaciones corporales: hábiles y torpes, fuertes y débiles, bellos y feos, normales y anormales.

Los deportes y los juegos escolares son los mismos juegos de guerra del pedagogo prusiano Guts Muths (1759-1839), los juegos pro-patria para defender la bandera (Mosse, 2000); son también la piedra angular del imperio británico y de ese monstruo llamado capitalismo, que maduró en la revolución industrial del siglo XIX y en el período de entreguerras mundiales del siglo XX. Efectivamente, las políticas de reclutamiento de la infancia siempre han estado presentes desde las mentalidades más obcecadas de intelectuales y políticos.

\section{Consideraciones finales}

La biopolítica que actuó sobre la educación física y el deporte escolar en la lógica del vigor de la nación (del mejoramiento de la raza), del regeneracionismo físico y moral ha servido para mantener el statu quo de las clases dirigentes del Estado - las oligarquías clientelares del poder-. Hoy este dispositivo de superación nacional continúa vigente, despojado de todo aparente régimen disciplinario coercitivo, pero en forma sociedad in-segura, pero obediente y sometida a la vigilancia y al control.

Los fenómenos de resistencia y oposición no parece que vayan a ir más allá, por el momento, de lo circunstancial y episódico, de lo marginal y periférico. Eso sí, con su capacidad de adaptación y las formas suaves que adopta el neoconservadurismo, siempre se dejarán intersticios o espacios en el que puedan actuar, sin poner en cuestión el sistema, quienes, en el sector público o en el privado, sigan creyendo en el ideal de la educación como un bien público, es decir como un instrumento de ciudadanía, de igualdad, de libertad y de formación de mentes críticas (Viñao, 2012,p. 106)

En los códigos disciplinares de la educación física subyace la acción de diferentes campos de poder (militar, médico, religioso, soberano, policial y jurídico o el económico), a cada cual su cometido, pero implícitamente cómplices sobre una única realidad metafísica 
que legitima la sobrevivencia de cada uno de estos poderes: la dominación. La educación física, como el deporte, entrarían a configurar parte importante del nuevo poder disciplinario que cita Foucault (1998, p. 37), de ese poder burgués -inventado por las clases dirigentes- «que ya no puede ser transmitido en términos de la soberanía» y, por lo tanto, ha servido de «instrumento fundamental de la constitución del capitalismo industrial y del tipo de sociedad que le es correlativo».

Foucault argumentó que el poder disciplinar surgió con la llegada de las instituciones modernas y se extendió a través de la sociedad moderna, de tal modo que las continuidades en las relaciones de poder no son solo evidentes en las escuelas, hospitales, prisiones, sino también fuera de éstas. Con el concepto de poder disciplinar cambian explícitamente los análisis sobre el poder, desde al ámbito macro de las estructuras e ideologías hasta el ámbito micro de los cuerpos y las prácticas cotidianas.

Las ideas de Foucault pueden aplicarse a la interpretación de la educación y el deporte, a través de esta «caja herramientas» conceptual que nos ofrece el filósofo francés. Sobre el inmenso escenario de conceptos e hipótesis foucaultianas es preciso navegar con cautela, quitar toda veneración fetichista hacia la obra y su autor y realizar un uso práctico pero creativo de sus aportaciones; una caja de herramientas teórica donde el investigador interesado pueda servirse por sí mismo. Los escritos de Foucault nos permiten elegir entre una multiplicidad de herramientas, ya que «muchas de sus preocupaciones siguen siendo las nuestras, y también algunas de sus muchas contradicciones» (Cuesta, 2013, p. 90).

\section{Referencias}

Alijo, J. (1902, 8 de octubre). Patronato en las prisiones. Revista de prisiones (Conclusión I), pp. 538-239.

Alijo, J. (1903, 1 de julio). Estudios antropológicos. Revista de las prisiones, pp. 282-284.

Ayala, I. M., y Zagalaz, M. L. (2016). «Gimnasia, Música y

Patria»: exhibiciones gimnásticas en el franquismo. El caso de los Festivales salesianos y el XIV Campeonato Nacional de Gimnasia Educativa. Retos: nuevas tendencias en educación física, deporte y recreación, 30, 114-124. https:/ /doi.org/10.47197/retos.v0i30.49026

Ayuntamiento de Barcelona (1839). Bando general de buen gobierno, ó de policia urbana, para esta ciudad de Barcelona. Barcelona: Imp. De Tomás Gaspar.

Ayuntamiento de Barcelona (1857). Ordenanzas municipales de Barcelona: Barcelona. Imp. de Nueva de J. Jepus y R.
Villegas.

Ayuntamiento de Barcelona (1914). Anuario Estadístico de la Ciudad de Barcelona 1912. Barcelona: Imp. Erich.

Barrenillo (1917, 30 de mayo). Por la cultura. Mundo Gráfi$c o$, p. 10.

Brasó, J., y Torrebadella, X. (2015). «El marro», un juego tradicional y popular en la educaciónfísica española (18071936). Revista Complutense de Educación, 26(3), 697-719. h t tp: / / dx.doi org/ $10.5209 /$ rev_RCED.2015.v26.n3.44680

Brasó, J., y Torrebadella, X. (2017a). ¿Por qué nos hacen jugar en la escuela? Reflexiones pedagógicas para (¿criticar?) entender la enseñanza actual. En R. Mínguez y E. Romero (Coord.), CITE. XIV Congreso de Teoría de la Educación. Murcia 21 y 23 de noviembre de 2017. La educación ante los retos de una nueva ciudadanía (pp. 541-549). Murcia: Universidad de Murcia.

Brasó, J., y Torrebadella, X. (2017b). El juego motor del marro: una indagación acerca de sus raíces pedagógicas. Revista de Dialectología y Tradiciones Populares, 72(1), 245264. doi: 10.3989/rdtp.2017.01.010

Brasó, J., y Torrebadella, X. (2018). El juego del marro. Un dispositivo de la pedagogía disciplinar en la tradición inventada de la educación física contemporánea del siglo XIX y principios del XX. Lúdica Pedagógica, 1(27), 85-96.

Brasó, J., y Torrebadella, X. (2019a). El juego del marro y la genealogía pedagógica y sociológica del poder disciplinar del deporte. Athenea Digital, 19(3), e2364. https:/ / doi.org/10.5565/rev/athenea.2364

Brasó, J., y Torrebadella, X. (2019b). Integrismo religioso y nacional en España. El ataque contra las escuelas laicas de Andrés Manjón (1910). Paulo Freire. Revista de Pedagogía Crítica, 21, 186-213. https://doi.org/10.25074/ 07195532.21 .1184

Cadalso, F. (1895, 23 de septiembre). Crónica extranjera. Revista de las prisiones, pp. 533-535.

Cadalso, F. (1898, 24 de diciembre). El reformatorio de Elmira. Revista de prisiones y de policía, pp. 461-463.

Calvo, F. (2012). Escuela, espacio y poder. Estudios sobre la educación y territorio. Barcelona: UOC.

Castel, R. (2013). Michel Foucault y la historia del presente. Con-ciencia social: anuario de didáctica de la geografia, la historia y las ciencias sociales, 17, 93-99.

Clausewitz, K. (1984). De la guerra. Barcelona: Labor.

Cuesta, R. (2007). Los deberes en la memoria de la educación. Madrid: Octaedro.

Cuesta, R. (2013). Las mil y una inquietudes de la obra de Foucault. Con-ciencia social, 17, 79-92.

Cuesta, R. (2014). Genealogía y cambio conceptual. Educación, historia y memoria. Education policy analysis archi- 
ves, 22 (23), 1-25 http://dx.doi.org/10.14507/ epaa.v22n23.2014

Cuesta, R. (2015). La venganza de la memoria y las paradojas de la historia. Salamanca: Lulu.com.

De Cossío, M. (1919, 1 de diciembre). «Porta Coeli» Asilo de niños golfos. Voluntad, pp. 29-31.

Díaz de Benjumea, N. (1866, 27 de julio). Palmerston y el pueblo inglés. Revista Hispano-Americana, pp. 10-18.

Dorado, P. (1898). El Reformatorio de Elmira. Estudio de derecho penal preventivo Madrid: La España Moderna.

Emiliozzi, M. V. (2016). Herramientas conceptuales en la obra de Michel Foucault para pensar la investigación del sujeto de la Educación. En E. Langer y B. Buenaventura (comp.), Usos y prospectivas de Foucault en la educación a 30 años de su muerte (pp. 47-57). Rada Tilly: Del Gato Gris.

Foucault, M. (1991). Saber y verdad. Madrid: La Piqueta.

Foucault, M. (1998). Genealogía del racismo. La Plata:Altamira. Foucault, M. (2000). Defender a la sociedad. Madrid: Akal.

Foucault, M. (2001a). El nacimiento de la clínica: una arqueología de la mirada médica. México: Siglo XXI.

Foucault, M. (2001b). Los anormales. Madrid: Akal.

Foucault, M. (2002). Arqueología del saber. México: Fondo de Cultura Económica.

Foucault, M. (2008). Seguridad, Territorio, Población. Madrid: Akal.

Foucault, M. (2010). El coraje de la verdad-el gobierno de síy de los otros II. Buenos Aires: Fondo de Cultura Económica de Argentina.

Foucault, M. (2012a). Historia de la sexualidad I. La voluntad de saber. Madrid: Biblioteca Nueva.

Foucault, M.(2012b). Vigilar y castigar. Nacimiento de la prisión. Madrid: Biblioteca Nueva.

Foucault, M. (2014). Nietzsche, la genealogía, la historia. Valencia: Pre-textos.

Foucault, M. (2018). La sociedad punitiva. Madrid: Akal.

Galak, E. (2013). Paradojas de la epistemología de la Educación Física argentina: verdad, identidad y doxa en la formación superior. En Epistemologia, ensino e crítica. Desafios contemporâneos para a Educação Física (pp. 193-220). Nova Metrópolis: Nova Armonia.

Huarte de San Juan, J. (1593). Examen de Ingenios para las ciencias. [Amberes]: Oficina Plantiniana.

Huarte de San Juan, J. (1594). Examen de Ingenios para las ciencias. Baeza: Juan Baptista de Montoya.

Huertas, R. (1998). Niños degenerados: medicina mental y «regeneracionismo» en la España del cambio de siglo. Dynamis:Acta hispanica ad medicinae scientiarumque historiam illustrandam, 18, 157-179.

Kopelovich, P. (2019). Biopoder y Departamento de Cultura Física (Universidad Nacional de La Plata, 1929-1946).
Ágora para la educación fisica y el deporte, 21, 170-192. https:/ /doi.org/10.24197/aefd.0.2019.170-192

Mateos, J., y Mainer, J. (2019). Políticas educativas e historia de la educación: una mirada genealógica, integradora y crítica. Paulo Freire. Revista De Pedagogía Crítica, 20, 41-67. https:/ /doi.org/10.25074/07195532.20.1086

Mosse, G. L. (2000). La imagen del hombre. La creación de la moderna masculinidad. Madrid:Talasa.

Pich, S., y Rodríguez, N. B. (2014). Los cuerpos de Foucault: una genealogía de los estudios foucaultianos en el campo de académico de la Educación Física en Brasil y en la Argentina. Revista Brasileira de Educação Física e Esporte, 28(3), 453-467.

Pich, S., y Vicente, M. (2021). Los conceptos foucaultianos de discurso y la producción académica de la educación física brasileña: diálogos, problematizaciones y devenires. Retos: nuevas tendencias en educación física, deporte y recreación, 39, 870-879. https://doi.org/10.47197/ retos.v0i39.77804

Rodríguez Giménez, R. (2003). Educación Física y dictadura: el cuerpo militarizado. Revista Brasileira de Ciências do Esporte, 25(1), 101-103.

Rodríguez Giménez, R. (2010). Notas para una investigación sobre pedagogía y biopolítica. Educación fisica y deporte, 29(2), 215-223.

Ros, A., y Torrebadella, X. (2021). Deconstruyendo y (re)construyendo el juego de «La bandera» de BadenPowell. Revista Foro de Educación, 19(2), 335-362. http: / / dx.doi.org/10.14516/fde.728

Russell, B. (1988). La educación y el orden social. Barcelona: Edhasa.

Salillas, R. (1905a). Caso de alarma social. Revista de penitenciaria, vol. 2, pp. 421-435.

Salillas, R. (1905b). Información extranjera. Lo Bueno y lo malo en las prisiones de los Estados Unidos de Norte América. Revista de penitenciaria, vol. 2, pp. 727-731.

Torrebadella-Flix, X., y Brasó, J. (2017). Barcelona y el problema de la educación física en la primera enseñanza a principios del siglo XX. Las Escuelas Catalanas del Distrito VI. Revista Brasileira de História da Educação, 17(2), 135-173. http://dx.doi.org/10.4025/rbhe.v17,n2.915 Torrebadella-Flix, X., yVicente-Pedraz, M. (2016). La gimnástica como dispositivo antionanista en la conformación de la educación física escolar en el siglo XIX en España. El nacimiento de una disciplina escolar. Movimento, 22(1), 99-114.http://dx.doi.org/10.22456/1982-8918.53986 Torrebadella-Flix, X., y Vicente-Pedraz, M. (2017). En torno a los orígenes del fútbol como deporte escolar en España (1883-1936). De moda recreativa a dispositivo disciplinario. Educación Física y Ciencia, 19(1), e018.https:/ 
/doi.org/10.24215/23142561e018

Torrebadella, X. (2013). Cuerpos abandonados y rescatados. La educación física en los orfanatos españoles del siglo XIX. Cabás, 10, 11-28.

Torrebadella, X. (2014). La influencia de la profesión médica en la educación física española del siglo XIX: Análisis social del Manual popular de gimnasia de sala, médica e higiénica del Dr. Schreber. Cultura, Ciencia y Deporte, 9(26), 163-176. http: / / dx.doi.org/10.12800/ccd.v9i26.434

Torrebadella, X. (2017). La militarización de la educación física escolar. Análisis de dos imágenes publicadas en la prensa de Barcelona de principios del siglo XX. Historia Social y de la Educación, 6(1), 78-108. doi:10.17583/ hse.2017.2393

Torrebadella, X. (2018). «Ludos pro Patria»: Aprender a disparar para salvar la nación. La Razón Histórica. Revista hispanoamericana de Historia de las Ideas, 40, 133-164.

Torrebadella, X. (2020). La escolarización de la educación física. Un análisis de cinco imágenes publicadas en la prensa de Barcelona de principios del siglo XX (19101913). Revista Brasileira de História da Educação, 20. DOI: http:/ /dx.doi.org/10.4025/rbhe.v20.2020.e115

Torrebadella, X. (2022). «Ladrones de la infancia». La educación física española entre 1909 y 1914. Revista Educación, politica y Sociedad, 7(1), 103-145. https: / /doi.org/ 10.15366/reps2022.7.1.005

Torrebadella, X., y Brasó, J. (2019). El patriotismo nacionalizador del padre Andrés Manjón y la «nueva pedagogía católica» en la educación física española (18891936). Revista de Estudios y Experiencias en Educación, 18(36), 137-159. doi: 10.21703/rexe.20191836torrebadella7

Torrebadella, X., y Inglés, E. (2021). II Demostración Nacional y los primeros campamentos de verano de la Organización Juvenil (1937-1939) deFET y de las JONS. RICYDE. Revista Internacional de Ciencias del Deporte, 17(66), 321-344. https: / /doi.org/10.5232/ricyde2021.06603

Vázquez García, F. (2019). La campaña contra los sacerdotes pederastas (1880-1912): un ejemplo de «pánico moral» en la España de la Restauración. Hispania, 78(260), 759-786. http://dx.doi.org/10.3989/hispania.2018.018

Veyne, P. (1984). Cómo se escribe la historia. Foucault revoluciona la historia. Madrid: Alianza Editorial.

Vicente-Pedraz, M. (2016). Veinte preguntas para pensar (críticamente) la educación física escolar. Educación Física y Deporte, 5(1), 11-41, http://doi.org/10.17533/ udea.efyd.v35n1a01

Vicente-Pedraz, M., y Torrebadella-Flix, X. (2015). La gimnástica como dispositivo antionanista en la conformación de la educación física escolar en el siglo XIX en España. Recepción de los discursos. Movimento, 21(4), 1037-1049. https: / / doi.org/10.22456/1982-8918.53986

Vicente-Pedraz, M., y Torrebadella-Flix, X. (2017). El dispositivo gimnástico en el contexto de la medicina social decimonónica española. De las políticas higiénicas a los discursos fundacionales de la «educación física». Asclepio, 69(1), p172. doi: http://dx.doi.org/10.3989/ asclepio.2017.04

Vicente-Pedraz, M., y Torrebadella-Flix, X. (2019). Los primeros gimnasios higiénicos: espacios para sanar y corregir el cuerpo. Disparidades. Revista de Antropología, 74(1): e011 https:/ / doi.org/10.3989/dra.2019.01.011

Vicente, M. (2011). Escuela y educación física en el contexto de la enseñanza por competencias. Reflexiones genealógicas desde la pedagogía crítica. Cultura, Ciencia, Deporte, 18(6), 161-170.

Vicente, M. (2012). El discurso técnico de la educación física o el techo de cristal: Bosquejo de un debate sobre el código disciplinar de la educación física y su precaria legitimidad. Estudios pedagógicos (Valdivia), 38 (Especial), 89-109.

Vicente, M. (2016). Bases para una didáctica crítica de la educación física. Apunts. Educación Física y Deportes, 123, 76-85.

Vigarello, G. (2005). Corregir el cuerpo. Historia de un poder pedagógico. Buenos Aires: Nueva Visión.

Viñao,A. (2012). Historia de las disciplinas, profesionalización docente y formación deprofesores: el caso español. ProPosições, 23(3), 103-118.

Viñao, A. (2016). La Historia de la Educación como disciplina y campo de investigación: viejas y nuevas cuestiones. Espacio, Tiempo y Educación, 3(1), 21-42. doi: http:/ / dx.doi.org/10.14516/ete.2016.003.001.3

\section{(Footnotes)}

1 Edición príncipe en Baeza, 1575 y editado Pamplona (1578), en Valencia, Bilbao y Lyon (1580), en Huesca (1581), en Venecia (1582, 1586, 1590), en Cremona (1588), en París (1588), en Leyden (1591), en Amberes (1593) y en Londres (1594). Fue catalogado en el índice libros prohibidos (Madrid, 1583), por lo que en 1594 volvió a ser publicado por su hijo Luis Huarte, después de pasar la censura de la Inquisición. Es la obra científica castellana más importante del siglo XVI y fue traducida al latín, inglés francés, italiano, holandés y alemán. Aparte contó con numerosas ediciones a lo largo del siglo XVII. Es una lástima y también una rareza que, de este autor tan célebre, que solamente escribió esta obra, se conozca muy poco de su vida. 